\title{
Assessment of Occupational Hazardsthat Affecting Male Fertility in Baghdad City
}

\author{
Hawraa Hussein Ghafel, $\mathrm{PhD}^{*}$ \\ *Lecturer at, Maternal and Neonate Nursing Department, College of Nursing, University of Baghdad
}

\begin{abstract}
:
Objectives: Identify the occupation of infertile men, Assess the occupational hazards that affects male fertility in Baghdad city \&Assessthe causes of male infertility inBaghdad city

Methodology: A non-probability (purposive) sample consists of (60) infertile men who were selected from fertility centers in Baghdad City. The study group consists of (60) infertile men who had infertility (causes of infertility related to them), the criteria for this sample include infertile men with different educational levels, different types of occupations and different types of diseases that prevent them from conceive .

Results:The study shows that military occupation as soldier is the dominant occupation among the infertile males $(21.7 \%$ \& $20 \%)$, followed by the office employer (16.7\%), then lumper $(13.3 \%)$, and low percentage are showed with baker occupation $(10 \% \& 8.3 \%)$. The urinary tract infection, abnormal semen analysis, and low sperm count are significant medical conditions that related to infertility among infertile men. The majority of infertile men having regular sexual intercourse (91.7\%), and most of the infertile men in this study doing sex with their wives in the ovulation days $(71.7 \%)$, the average sexual intercourse number is three time per week (50\%). This table indicated also that only $16.7 \%$ of the infertile men having impotence, $31.7 \%$ of them having premature ejaculation, and $15 \%$ of them having delayed ejaculation, while only two using lubricant during their sexual intercourse. The statistical methods that used in this study were (Frequency and Percentage).

Conclusions: This study show that military occupation as solider is the dominant occupation among the infertile males for both previous occupation and current. The exposure to the temperature, noise at work, existence of communication towers, and feeling of stress and tension at work, eating in the disposable dishes that made from chemical substances that effected by high temperature and they travelling between towns by hammer cars that don't have any air conditions or ventilations and that make the environment inside care is very hot and that causes harmful effects on the sperms productions all these significant hazards related to occupation among infertile men. The evidence of the occupational hazards effect is obtained through their effects on the men fertility, these effects different according to the type of occupation and the exposure. The reproductive effects include abnormal sperm quality, low sperm count and azoospermia .In addition decreased the number of intercourse that decrease the chances of pregnancy occur.
\end{abstract}

Keywords: Infertility, male Infertility, Occupation, occupational Hazard, Professional Standers.

\section{Introduction}

Infertility is the inability of couples to conceive related to abnormality in the reproduction functioning of male and female. Approximately one-third of infertility is related to the female, one-third related to the male causes and one-third is a combination between male and female together and one-third of problems in both partners or, is unexplained ${ }^{(1)}$. Infertility affects an estimated $15 \%$ of couples globally, amounting to 48.5 million couples. Males are found to be solely responsible for $20-30 \%$ of infertility cases and contribute to $50 \%$ of cases overall. However, this number does not accurately represent all regions of the world. Indeed, on a global level, there is a lack of accurate statistics on rates of male Infertility ${ }^{(2)}$. Workplace exposures and hazards have effects on many organ systems in the body including the reproductive system. The evidence of the reproductive effects of occupational hazards is obtained through their effects on the men fertility these effects different and overlap due to the multiple nature of exposures in the workplace. Hazardous agents include pesticides, chemical agent and heavy metals. The reproductive effects include reduced fecundity, abnormal sperm quality, low sperm count and permanent sterility ${ }^{(3)}$.Environmental agents can adversely affect germ cell development at many different stages from proliferating spermatogonia to mature spermatozoa. Although they have been shown to affect male reproductive function in animals ${ }^{(4)}$.Ther are many types of treatment that found to treated male infertility the patient with speramtooza have difficulties in treatment because ther is no effective treatment for this case Although many evidence ensuring that that many infertile male have a genetic causes that effect fertility, the cause has not been elucidated in the cases ${ }^{(5)}$. 


\section{Methodology}

A non-probability (purposive) sample consists of (60) infertile men who were selected from fertility centers in Baghdad City .The study group consists of (60) infertile men who had infertility (causes of infertility related to them), the criteria for this sample include infertile men with different educational levels, different type of occupation and different type of diseases that prevent them from conceive .The data collected through using questionnaire that answered by the infertile men they follow up to the fertility centers in Iraq. The questionnaire constructed after reading many previous literatures and previous researches and studies related to this topic. The questionnaire consist of four main parts the first part consist of demographic data such as (age, educational level, occupational status, social status) occupational status: including ten items regarding current occupation ,previous occupation, if the infertile man affected by radiation or chemical substances in his work, exposure to high heat, exposure to microwaves, exposure to noisy, air pollution ,driving the car for long time , stress, chemical fumes in his current and previous work and the effect of previous occupation on the results of seminal fluid . social status consist of two items, the first one including ( married, single or polygamous ) and the second item regarding smoking status including ( smoker, nonsmoker, the number of cigarette per day if he smoker and the passive smoking. The second main part regarding the previous medical history for infertile men and consist of twelve item that include ( infections of the reproductive system, UTI, varicocele , trauma of the tests , mumps, DM, heart diseases, abnormal seminal fluid analysis, oligospermia , immobility of the sperms, abnormality of sperms and azoospermia). The main third part of the questionnaire regarding reproductive status that include ( if the man using herbal for treated the infertility ,the infertility period, type of infertility, any relative that have infertility and the degree of consanguinity). finally the fourth part regarding sexual status including (regularity of coitus, the coitus occur in the ovulation time or not, the number of coitus per week, the man suffering from: sexual dysfunction, premature ejaculation, delay ejaculation ) and finally using any lubricants or cream with coitus.

\section{Results:}

\section{Results And Findings:}

Table 1: Distribution of the Sample according to their Demographic Characteristics

\begin{tabular}{|c|c|c|c|c|}
\hline No & Characteristics & & $\mathbf{F}$ & $\%$ \\
\hline \multirow[t]{6}{*}{1} & \multirow[t]{6}{*}{ Age: } & $>20$ years & 1 & 1.7 \\
\hline & & $20-29$ years & 19 & 31.7 \\
\hline & & $30-39$ years & 31 & 51.7 \\
\hline & & $40-49$ years & 8 & 13.3 \\
\hline & & $50 \leq$ years & 1 & 1.7 \\
\hline & & Total & 60 & 100 \\
\hline \multirow[t]{7}{*}{2} & \multirow[t]{7}{*}{ Educational level: } & Doesn't read \& write & 1 & 1.7 \\
\hline & & Primary & 12 & 20 \\
\hline & & Intermediate & 23 & 38.3 \\
\hline & & Secondary & 6 & 10 \\
\hline & & Institute/College & 17 & 28.3 \\
\hline & & Higher education & 1 & 1.7 \\
\hline & & Total & 60 & 100 \\
\hline \multirow[t]{4}{*}{3} & \multirow[t]{4}{*}{ Marital status: } & Previously married & 16 & 26.7 \\
\hline & & Previously unmarried & 41 & 68.3 \\
\hline & & Polygamous & 3 & 5 \\
\hline & & Total & 60 & 100 \\
\hline \multirow[t]{3}{*}{4} & \multirow[t]{3}{*}{ Smoking: } & Yes & 20 & 33.3 \\
\hline & & No & 40 & 66.7 \\
\hline & & Total & 60 & 100 \\
\hline \multirow[t]{4}{*}{5} & \multirow{4}{*}{$\begin{array}{l}\text { Number of cigarette per } \\
\text { day: }\end{array}$} & None & 41 & 68.3 \\
\hline & & $<20$ & 6 & 10 \\
\hline & & $>20$ & 3 & 21.7 \\
\hline & & Total & 60 & 100 \\
\hline \multirow[t]{3}{*}{$\overline{6}$} & \multirow[t]{3}{*}{ Smoker family member: } & Yes & 21 & 35 \\
\hline & & No & 39 & 65 \\
\hline & & Total & 60 & 100 \\
\hline
\end{tabular}

No: Number, F: Frequency, \%: Percentage

This table reveals that more than half of infertile men are fall in age group between 30-39 years old $(51.7 \%)$ who are graduated from intermediate school $(38.3 \%)$ and $28.3 \%$ are institute or college graduated . $68.3 \%$ of them are previously unmarried and only $5 \%$ are polygamous. Regarding smoking status, the findings 
show that only $20 \%$ of infertile men are smoking less than two cigarettes per day (10\%), and only $35 \%$ of them having a smoker in family member.

Table 2: Distribution of the Sample according to their Occupation

\begin{tabular}{|c|l|c|c|c|c|}
\hline \multirow{2}{*}{ No } & \multirow{2}{*}{ Occupation } & \multicolumn{2}{c|}{ Previous Occupation } & \multicolumn{2}{c|}{ Current Occupation } \\
\cline { 2 - 5 } & Guard & $\mathbf{F}$ & $\mathbf{\%}$ & $\mathbf{F}$ & $\mathbf{\%}$ \\
\hline 1 & 1 & 1.7 & 1 & 1.7 \\
\hline 2 & Soldier & $\mathbf{1 3}$ & $\mathbf{2 1 . 7}$ & $\mathbf{1 2}$ & $\mathbf{2 0 . 0}$ \\
\hline 3 & Nurse & 1 & 1.7 & 1 & 1.7 \\
\hline 4 & Baker & $\mathbf{6}$ & $\mathbf{1 0 . 0}$ & $\mathbf{5}$ & $\mathbf{8 . 3}$ \\
\hline 5 & Policeman & 3 & 5.0 & 3 & 5.0 \\
\hline 6 & Student & 3 & 5.0 & 3 & 5.0 \\
\hline 7 & Office employer & $\mathbf{1 0}$ & $\mathbf{1 6 . 7}$ & $\mathbf{1 0}$ & $\mathbf{1 6 . 7}$ \\
\hline 8 & Fashion designer & 1 & 1.7 & 1 & 1.7 \\
\hline 9 & Engineer & 2 & 3.3 & 2 & 3.3 \\
\hline 10 & Teacher & 2 & 3.3 & 2 & 3.3 \\
\hline 11 & Porter & 1 & 1.7 & 1 & 1.7 \\
\hline 12 & Lumper & $\mathbf{8}$ & $\mathbf{1 3 . 3}$ & $\mathbf{8}$ & $\mathbf{1 3 . 3}$ \\
\hline 13 & Driver & 2 & 3.3 & 2 & 3.3 \\
\hline 14 & Painter & 0 & 0 & 1 & 1.7 \\
\hline 15 & Carpenter & 3 & 5.0 & 3 & 5.0 \\
\hline 16 & Smith & 1 & 1.7 & 1 & 1.7 \\
\hline 17 & Farmer & 1 & 1.7 & 1 & 1.7 \\
\hline 18 & Shop owner & 1 & 1.7 & 1 & 1.7 \\
\hline 19 & Grocery & 0 & 0 & 1 & 1.7 \\
\hline 20 & Car mechanic & 1 & 1.7 & 1 & 1.7 \\
\hline & Total & $\mathbf{6 0}$ & $\mathbf{1 0 0}$ & $\mathbf{6 0}$ & $\mathbf{1 0 0}$ \\
\hline
\end{tabular}

No: Number, F: Frequency, \%: Percentage

This table shows that military occupation as soldier is the dominant occupation among the infertile males for both previous and current occupation $(21.7 \%$ \& $20 \%)$, followed by the occupation of office employer (16.7\%), then lumper (13.3\%), and low percentage are showed with baker occupation (10\% \& 8.3\%)

Table 3: Occupational Hazards that Affect Male Infertility $(\mathrm{N}=60)$

\begin{tabular}{|c|l|c|c|c|c|}
\hline \multirow{2}{*}{ No } & \multirow{2}{*}{ Occupational Hazards } & Yes & No & \multirow{2}{*}{ M } & \multirow{2}{*}{ Sig. } \\
\cline { 3 - 3 } & & $\mathbf{F ~ ( \% )}$ & $\mathbf{F ~ ( \% )}$ & & \\
\hline 1 & Exposure to radiation and chemical materials & $3(5)$ & $57(95)$ & 0.05 & N.S \\
\hline 2 & Exposure to high temperature during the work & $28(46.7)$ & $32(53.3)$ & 0.47 & S \\
\hline 3 & Existence of communication towers in workplace & $27(45)$ & $33(55)$ & 0.45 & S \\
\hline 4 & Exposure to noise at work & $28(46.7)$ & $32(53.3)$ & 0.47 & S \\
\hline 5 & Air pollution in the workplace & $16(26.7)$ & $44(73.3)$ & 0.27 & N.S \\
\hline 6 & Driving the car for long periods of time & $8(13.3)$ & $52(86.7)$ & 0.13 & N.S \\
\hline 7 & Feeling of stress and tension in work & $40(66.7)$ & $20(33.3)$ & 0.67 & S \\
\hline 8 & Inhalation of vapor and odors of chemicals at work & $13(21.7)$ & $47(78.3)$ & 0.22 & N.S \\
\hline 9 & $\begin{array}{l}\text { Semen analysis result changed due to former or } \\
\text { current work }\end{array}$ & $15(25)$ & $45(75)$ & 0.25 & \multirow{2}{*}{ N.S } \\
\hline
\end{tabular}

No: Number, F: Frequency, \%: Percentage, M: Mean, Sig.: Significance, N.S: Not significant (M=0-0.33), S: Significant (0.34-0.67), H.S: High significant (M=0.68-1)

This table shows that exposure to temperature, noise at work, existence of communication towers, and feeling of stress and tension at work are significant hazards related to occupation among infertile men.

Table 4: Previous Medical History for the Infertile Men $(\mathrm{N}=60)$

\begin{tabular}{|c|c|c|c|c|c|}
\hline \multirow{2}{*}{ No } & \multirow{2}{*}{ Medical condition } & Yes & No & \multirow{2}{*}{ M } & \multirow{2}{*}{ Sig. } \\
\hline & & F (\%) & F (\%) & & \\
\hline 1 & Reproductive tract infection & $20(33.3)$ & $40(66.7)$ & 0.33 & N.S \\
\hline 2 & Urinary tract infection & $25(41.7)$ & $35(58.3)$ & 0.42 & $\mathrm{~S}$ \\
\hline 3 & Varicocele & $10(16.7)$ & $50(83.3)$ & 0.17 & N.S \\
\hline 4 & Testes stroke & $9(15)$ & $51(85)$ & 0.15 & N.S \\
\hline 5 & Mumps & $9(15)$ & $51(85)$ & 0.15 & N.S \\
\hline 6 & Diabetes mellitus & $1(1.7)$ & $59(98.3)$ & 0.02 & N.S \\
\hline 7 & Cardiovascular disease & $4(6.7)$ & $56(93.3)$ & 0.07 & N.S \\
\hline
\end{tabular}


Assessment of Occupational Hazardsthat Affecting Male Fertility in Baghdad City

\begin{tabular}{|c|l|c|c|c|c|}
\hline 8 & Abnormal semen analysis & $25(41.7)$ & $35(58.30$ & 0.42 & S \\
\hline 9 & Low sperm count & $26(43.3)$ & $34(56.7)$ & 0.43 & S \\
\hline 10 & Sperm's immobility & $20(33.3)$ & $40(66.7)$ & 0.33 & N.S \\
\hline 11 & Abnormal sperm's morphology & $14(23.3)$ & $46(67.7)$ & 0.23 & N.S \\
\hline 12 & Azoospermia & $7(11.7)$ & $53(88.3)$ & 0.12 & N.S \\
\hline
\end{tabular}

No: Number, F: Frequency, \%: Percentage, M: Mean, Sig.: Significance, N.S: Not significant (M=0-0.33), S: Significant (0.34-0.67), H.S: High significant (M=0.68-1)

This table depicts that urinary tract infection, abnormal semen analysis, and low sperm count are significant medical conditions that related to infertility among infertile men.

Table 5: Reproductive Status of Infertile Men

\begin{tabular}{|c|l|l|c|c|}
\hline No & Reproductive Status & F & \% \\
\hline 1 & \multirow{2}{*}{ Using of infertility booster herbs: } & Yes & 20 & 33.3 \\
\cline { 3 - 5 } & & No & 40 & 66.7 \\
\cline { 3 - 5 } & & Total & 60 & 100 \\
\hline 2 & \multirow{2}{*}{ Duration of infertility: } & $1-5$ years & 42 & 70 \\
\cline { 3 - 5 } & & $6-10$ years & 13 & 21.7 \\
\cline { 3 - 5 } & & $11 \leq$ years & 5 & 8.3 \\
\cline { 3 - 5 } & & Total & 60 & 100 \\
\hline 3 & \multirow{2}{*}{ Type of infertility: } & Primary & 46 & 76.7 \\
\cline { 3 - 5 } & & Secondary & 14 & 23.3 \\
\cline { 3 - 5 } & & Total & 60 & 100 \\
\hline 4 & \multirow{2}{*}{ Having infertile relative: } & Yes & 14 & 23.3 \\
\cline { 3 - 5 } & & No & 60 & 76.7 \\
\cline { 3 - 5 } & & Total & 17 & 28.3 \\
\hline 5 & \multirow{2}{*}{ Degree of kinship: } & Fist degree & 2 & 3.3 \\
\cline { 3 - 5 } & & Second degree & 41 & 68.3 \\
\cline { 3 - 5 } & & Strange & 60 & 100 \\
\cline { 3 - 5 } & & Total & & \\
\hline
\end{tabular}

No: Number, F: Frequency, \%: Percentage

This table reveals only $33.3 \%$ of infertile men are using herbs as fertility booster, $76.7 \%$ of them having primary infertility for the period of $1-5$ years $(70 \%)$, the table also shows that $23.3 \%$ of their relative having infertility who are first degree (28.3\%) and second degree (3.3) relatives.

Table 6: Sexual Status of the Infertile Men

\begin{tabular}{|c|c|c|c|c|}
\hline No & Sexual Status & & $\mathbf{F}$ & $\%$ \\
\hline \multirow[t]{3}{*}{$\overline{1}$} & \multirow{3}{*}{ Regular sexual intercourse: } & Yes & 55 & 91.7 \\
\hline & & No & 5 & 8.3 \\
\hline & & Total & 60 & 100 \\
\hline \multirow[t]{3}{*}{2} & \multirow{3}{*}{$\begin{array}{l}\text { Having Sexual intercourse during } \\
\text { ovulation day for wife (day 12-18 of } \\
\text { menstrual cycle): }\end{array}$} & Yes & 43 & 71.7 \\
\hline & & No & 17 & 28.3 \\
\hline & & Total & 60 & 100 \\
\hline \multirow[t]{4}{*}{3} & \multirow[t]{4}{*}{ Number of sexual intercourse: } & $<3$ time/week & 11 & 18.3 \\
\hline & & 3 time/week & 30 & 50 \\
\hline & & $>3$ time/week & 19 & 31.7 \\
\hline & & Total & 60 & 100 \\
\hline \multirow[t]{3}{*}{$\overline{4}$} & \multirow[t]{3}{*}{ Impotence: } & Yes & 10 & 16.7 \\
\hline & & No & 50 & $\overline{83.3}$ \\
\hline & & Total & 60 & 100 \\
\hline \multirow[t]{3}{*}{5} & \multirow[t]{3}{*}{ Premature ejaculation: } & Yes & 19 & 31.7 \\
\hline & & No & 41 & 68.3 \\
\hline & & Total & 60 & 100 \\
\hline \multirow[t]{3}{*}{6} & \multirow[t]{3}{*}{ Delayed ejaculation: } & Yes & 9 & 15 \\
\hline & & No & 51 & 85 \\
\hline & & Total & 60 & 100 \\
\hline \multirow[t]{3}{*}{7} & \multirow[t]{3}{*}{ Using lubricant during intercourse: } & Yes & 2 & 3.3 \\
\hline & & No & 58 & 96.7 \\
\hline & & Total & 60 & 100 \\
\hline
\end{tabular}

No: Number, F: Frequency, \%: Percentage 
This table indicated that majority of infertile men having regular sexual intercourse (91.7\%), and most of them having sexual intercourse with their wives during the ovulation days $(71.7 \%)$, the average sexual intercourse number is three time per week (50\%). This table indicated also that only $16.7 \%$ of the infertile men having impotence, $31.7 \%$ of them having premature ejaculation, and $15 \%$ of them having delayed ejaculation, while only two using lubricant during their sexual intercourse.

\section{Discussion Of The Results:}

Age:This study show that more than half of infertile men are fall in age group between 30-39 years old $(51.7 \%)$ who are graduated from intermediate school $(38.3 \%)$ and $28.3 \%$ are graduated from institute or college. $68.3 \%$ of them are previously unmarried and only $5 \%$ are polygamous. Regarding smoking status, the findings show that only $20 \%$ of infertile men are smoking less than two cigarettes per day (10\%), and only $35 \%$ of them having a smoker in family member. The fertility rate in men younger than age 30 years has lack by $15 \%$. Agerelated infertility will persist to be a problem. A basic understanding of the issues is critical for a doctor so that they can effectively counsel infertile couple who are considering a delay in childbearing for social reasons or for those seeking fertility treatments. This review details the changes in fertility seen in the aging male ${ }^{(6) .}$

The results of this study were agree with previous study and show that fertility was significantly reduced for men with increase their ages because the quality of sperms in men decrease with age so the chances for conceive .decrease with older partners rather than with younger partners

\section{Occupation}

This study shows that military occupation as soldier is the dominant occupation among the infertile males for both previous and current occupation $(21.7 \% \& 20 \%)$, followed by the occupation of office employer $(16.7 \%)$, then lumper $(13.3 \%)$, and low percentage are showed with baker occupation $(10 \% \& 8.3 \%)$.

The Centre of Assisted Reproduction, (2010) stated that, theidea that some of occupations may expose the workers at risk of infertility related to damages or effect on reproductive system is not new. In 1860 a French scientist noted thatsome of some of occupational that can decrease the sperm quality include heat, pesticides, hydrocarbons, ionizing radiation and estrogens .A previousstudy from Australia identified occupations at risk to include transport workers, building industry workers, motor mechanics, farmers and miners ${ }^{(7)}$. In a study that investigated infertility risk factors by conducting a population-based case-control study in the military population of the French town of Brest. This study suggests that in this military population, having worked in very hot conditions, should be considered as risk factors for infertility ${ }^{(8)}$. In this study thehighest percentage of male fertility were military occupation as soldier is the dominant occupation among the infertile males for both previous and current occupation because they having worked in very hot conditions, should be considered as risk factors for infertility and some pleases was exposure to radiation and heavy metal substances from explosions in the current war with ISIS.

Some pesticides, heavy metals and industrial agents also reduce sperm production. Less is known about the effects of bisphenol A (BPA), an estrogen-like compound found in some water bottles and other plastics ${ }^{(9)}$.

In addition we cannot exclude the possibility of effects of stress and psychological difficulties linked to working in such conditions (very hot area, explosions, psychological pressure) related to the war . Occupational Hazards that Affect Male Infertility:This study shows that exposure to temperature, noise at work, existence of communication towers, and feeling of stress and tension at work are significant hazards related to occupation among infertile men. A hazard is any source of potential problems, harm or adverse health effects on something or someone suffering from certain conditions at work ${ }^{(10)}$.

The level of risk is often categorized upon the potential harm or adverse health effect that the hazard may cause, the number of times persons are exposed and the number of persons exposed ${ }^{(11)}$. The influence of working conditions, occupational exposures to potential chemical and physical reproductive toxic agents and psychological stress during work on male fertility. Significant associations were reported between impaired semen parameters and the chemical exposures; Psychological distress has another important contribution to infertility. Several studies indicated that stress has a negative impact on sperm parameters. Active production of sperm requires a temperature about $3-4^{\circ} \mathrm{C}$ lower than normal body temperature. This fact is supported by the decreased sperm count seen in pathologies such as varicocele and cryptorchidism, as well as in cases of prolonged sauna exposure and in paralyzed patients restricted to wheelchairs. The effect of chronic occupational exposure to high temperatures has been examined, in addition to in the welding profession, in the ceramics industry. Impairment of spermatogenesis has been found in a high prevalence among professional drivers, investigated infertility risk factors in a French military population and found heat exposure as an independent risk factor for male infertility. ${ }^{(12) .}$ This previous study results agree with this study .

:Previous Medical History for the Infertile Men

This study conducted that urinary tract infection, abnormal semen analysis, and low sperm count are significant .medical conditions that related to infertility among infertile men 
Some infections can interfere with sperm production or sperm health or can cause scarring that blocks the passage of sperm. These include inflammation of the epididymis (epididymitis) or testicles (orchitis) and some sexually transmitted infections, including gonorrhea or HIV. Although some infections can result in permanent testicular damage, most often sperm can still be retrieved. If the number of sperm in in semen (sperm count) is low, it decreases the odds that one of the sperm will fertilize the partner's egg. A low sperm count is fewer than 15 million sperm per milliliter of semen or fewer than 39 million per ejaculate ${ }^{(13)}$ In this study most men had reproductive tract infections and these infections affect the ability of sperms to fertilize, these infections may be transmitted to the wife and prevent pregnancy and this agrees with the previous study.

\section{Reproductive Status of Infertile Men:}

This table reveals only $33.3 \%$ of infertile men are using herbs as fertility booster, $76.7 \%$ of them having primary infertility for $1-5$ years duration of the infertility, (70\%) the table also shows that $23.3 \%$ of their relative having infertility who are first degree (28.3\%) and second degree (3.3) relatives. Some of studies suggested that using of some herbal treatment can be able to change the count of the sperm. When the semen analysis was done after the men taking the herbal treatment for 90 days the result found that the sperms increase related to taking the medication to a $167 \%$ increase in sperm concentration in men treated with Ashwagandharoot ${ }^{(14) .}$. In this study some of infertile male using honey and black seed in trying to increase the ability to conceive. The period of infertility, or time to pregnancy occur hasbeenusedas a major factor for timing routine explorationand starting treatment.It has been suggested that the longer the period, the lower is the probability of pregnancy occur, and therefore investigations are usually not started before one year of infertility. On the in addition, a long duration of infertility has also been proposed as an indication to use assisted reproductive technology (ART) ${ }^{(15)}$.

Infertility is have two types the first one is primary and the second type is secondary infertility. Definitions of primary infertility different between studies, but the operational definition, put forth by the WHO, defines primary infertility as the"Inability to conceive within two years of exposure .among women 15 to 49 ears oldSecondary infertility means that the inability to conceive following a previous pregnancy. In the world wide, most of infertile couples having primary infertility. The mean age of the women was 25.9 years (range: 16-30 years and the prevalence of primary infertility was 12.6 per cent [95\% Confidence Interval (CI): 10.5$15.0 \%$ ]. The important factor associated with primary infertility was HSV-2 seropositivity ${ }^{(16)}$.

In this study the results showthat the highest percentage of thetype of infertility is primary infertility rather than secondary infertility

\section{Sexual Status of the Infertile Men:}

This study indicated that majority of infertile men having regular sexual intercourse $(91.7 \%)$, and most of them having sexual intercourse with their wives during the ovulation days (71.7\%), the average sexual intercourse number is three time per week $(50 \%)$. This study indicated also that only $16.7 \%$ of the infertile men having sexual dysfunction, $31.7 \%$ of them having premature ejaculation, and $15 \%$ of them having delayed ejaculation, while only two using lubricant during their sexual intercourse .Problems with sex thesecan include trouble keeping or maintaining problems with an erection sufficient for sex (erectile dysfunction), premature ejaculation, painful intercourse, abnormalities such as having a urethral opening beneath the penis (hypospadias), or psychological or relationship problems that interfere with sex.Retrograde ejaculation occurs when semen enters the bladder during orgasm instead of emerging out the tip of the penis.Various health conditions can cause retrograde ejaculation, including diabetes, spinal injuries, medications, and surgery of the bladder, prostate or urethra ${ }^{(17)}$.

\section{Conclusion}

The type of occupation affect male fertility in Baghdad city, this study show that military occupation as solider is the dominant occupation among the infertile males for both previous and current occupation because solider exposure to high temperatures, noise, exposure to radiation, electromagnetic waves and many types of chemical substances, air pollution, automobile driving, stress and smoking in his work. The evidence of the occupational hazards effect is obtained through their effects on the men fertility these effects different according to the type of occupation and the exposure. The reproductive effects include abnormal sperm quality, low sperm count and azoospermia .In addition decreased sexual activity can decrease the chances of conception .

\section{Recommendations}

The study recommended that all infertile men with abnormal seminal fluid or suffering from infertility should be not exposed to high temperatures, noise, associated with manufacturing exposure to radiation, electromagnetic waves and a variety of chemical substances, air pollution, automobile driving for long time, 
stress and smoking because all these occupational hazards affecting the fertility and ability of men to conceive. The infertile male should be Follow the professional standards of safety.

\section{References:}

[1] The World Health Organization ( WHO) : Sexual and reproductive health, Global prevalence of infertility, infecundity and childlessness,2012.http://www.who.int/reproductivehealth/topics/infertility/burden/en/

[2] AshokAgarwal,corresponding author AditiMulgund, Alaa Hamada, and Michelle Renee Chyatte : A unique view on male infertility around the globe, 2015; 13:37.http://www.ncbi.nlm.nih.gov/pmc/articles/PMC4424520/

[3] Ashiru OA, Odusanya OO.: Fertility and occupational hazards: review of the literature, Afr J Reprod Health. 2009 Mar;13(1):15965http://www.ncbi.nlm.nih.gov/pubmed/20687273

[4] Yefim R. Sheynkin .: Environmental and Occupational Hazards and Male infertility, StonyBrook,2016.https://www.stonybrookmedicine.edu/patientcare/urology/occ_env_hazards_male_infertility

[5] ToshinobuMiyamoto,1 Akira Tsujimura,2 Yasushi Miyagawa,2 Eitetsu Koh,3 Mikio Namiki,3 and Kazuo Sengoku: Male Infertility and Its Causes in Human, Volume 2012 (2012), Article ID 384520, 7 pages.http://www.hindawi.com/journals/au/2012/384520/

[6] Isiah D Harris, Carolyn Fronczak, Lauren Roth, and Randall B Meacham :Fertility and the Aging Male , US National Library of Medicine National Institutes of Health, Journal List , Rev Urol ,13(4); 2011.https://www.ncbi.nlm.nih.gov/pmc/articles/PMC3253726/

[7] The Centre of Assisted Reproduction: Environmental Causes of Infertility,2010. http://www.chem-tox.com/infertility/.

[8] Juan Felipe Velez de la Calle, Emmanuelle Rachou, Marie-Thérèse le Martelot, BéatriceDucot, Luc Multigner and Patrick F. Thonneau:Male infertility risk factors in a French military population,2000, Oxford JournalsMedicine \& Health ,Human Reproduction,Volume 16, Issue 3,Pp. 481-486.http://humrep.oxfordjournals.org/content/16/3/481.long

[9] Beck M.: Surprising Causes of Male Infertility, The Wall Street Journal , U.S, 2011.http://www.wsj.com/articles/SB10001424052702303627104576411630724741052

[10] Canadian Centre for Occupational Health \& Safety: Hazard and Risk, 1997-2016 Canada. https://www.ccohs.ca/oshanswers/hsprograms/hazard_risk.html

[11] Health \& Safety Authority: Hazard and Risk,2016.http://www.hsa.ie/eng/Topics/Hazards/

[12] Einat K. SHEINER, EyalSHEINER, Rachel D. HAMMEL,Gad POTASHNIK and Refael CAREL: Effect of Occupational Exposures on Male Fertility: Industrial Health 62.https://www.jniosh.go.jp/oldsite/old/niih/en/indu_hel/2003/pdf/IH41_09.pdf
A.Mayo Foundation for Medical Education and Research: Diseases and Conditions Male infertility,

2016.http://www.mayoclinic.org/diseases-conditions/male-infertility/basics/causes/con-20033113 2014 Vol. 6 Issue 4.http://www.naturalmedicinejournal.com/journal/2014-04/ashwagandha-male-infertility

[15] Ivo Brosens1, Sylvie Gordts, Marion Valkenburg, PatrickPuttemans, Rudi Campo and Stephan Gordts: Investigation of the infertile couple: when is the appropriate time to explore female infertility,2014. Oxford Journals, Medicine\& Health ,Human Reproduction,Volume 19, Issue 8,Pp. 1689-1692.http://humrep.oxfordjournals.org/content/19/8/1689.full

[16] Adamson PC1, Krupp K, Freeman AH, Klausner JD, Reingold AL, Madhivanan P.: Prevalence \& correlates of primary infertility among young women in Mysore, India.https://www.ncbi.nlm.nih.gov/pubmed/22089604

[17] B.Mayo Foundation for Medical Education and Research: Diseases and Conditions Male infertility, 2016.http://www.mayoclinic.org/diseases-conditions/male-infertility/basics/causes/con-20033113

Hawraa Hussein Ghafel. "Assessment of Occupational Hazardsthat Affecting Male Fertility in Baghdad City." IOSR Journal of Nursing and Health Science (IOSR-JNHS) 6.4 (2017): 77-83. 